Brief Report

\title{
Study of Hypersensitivity to Malassezia furfur in Patients with Atopic Dermatitis with Head and Neck Pattern: Is It Useful as a Biomarker and Therapeutic Indicator in These Patients?
}

\author{
Francisco José Navarro-Triviño *(1) and Ángela Ayén-Rodríguez
}

check for updates

Citation: Navarro-Triviño, F.J.; Ayén-Rodríguez, Á. Study of Hypersensitivity to Malassezia furfur in Patients with Atopic Dermatitis with Head and Neck Pattern: Is It Useful as a Biomarker and Therapeutic Indicator in These Patients? Life 2022, 12, 299. https:// doi.org/10.3390/life12020299

Academic Editors: Jose Carlos Armario Hita, Jose Juan Pereyra Rodriguez and Ricardo

Ruiz-Villaverde

Received: 20 January 2022

Accepted: 14 February 2022

Published: 16 February 2022

Publisher's Note: MDPI stays neutral with regard to jurisdictional claims in published maps and institutional affiliations.

Copyright: (c) 2022 by the authors. Licensee MDPI, Basel, Switzerland. This article is an open access article distributed under the terms and conditions of the Creative Commons Attribution (CC BY) license (https:// creativecommons.org/licenses/by/ $4.0 /)$.
Department of Contact Eczema and Immunoallergic Diseases, Dermatology, Hospital Universitario San Cecilio, Avenida de la Investigación s/n, 18016 Granada, Spain; aayenrodriguez@gmail.com

* Correspondence: fntmed@gmail.com

\begin{abstract}
Atopic dermatitis (AD) is one of the most prevalent chronic inflammatory diseases. Head and neck $(\mathrm{H} \& \mathrm{~N})$ involvement, also known as the picture-frame pattern, can be a diagnostic and even therapeutic challenge. Sensitization to the fungus Malassezia furfur seems to be implicated in this clinical presentation. To investigate the role of Malassezia furfur in H\&N dermatitis, we performed an observational single-centre study. Serum-specific IgE levels for Malassezia furfur were determined in a total of 25 patients with $\mathrm{AD}$ (15 receiving dupilumab treatment, 10 not receiving dupilumab), 14 patients with seborrheic dermatitis, and 19 healthy controls. Reactivity to Malassezia furfur, in terms of serum-specific IgE levels ( $>0.35 \mathrm{Ku}$.arb./L), was found in $80 \%$ of patients with AD. Risk factors to consider include high total IgE levels, sensitization to multiple pneumoallergens, and elevated LDH and CRP levels. Prescription of topical antifungals, oral antifungals, or a combination of both showed good response in $100 \%$ of cases in the H\&N AD group treated with dupilumab. The most appropriate treatment seems to be the use of oral itraconazole and/or ketoconazole cream. The median treatment time was 3 weeks. Localized dermatitis in H\&N significantly affects the patient's life. We present a study of sensitization to Malassezia furfur in patients with H\&N AD. It is important to know the differential diagnosis and to approach the study correctly. Sensitization to Malassezia furfur may be one of the main reasons, especially in patients being treated with dupilumab. The use of antifungals allows for adequate control, avoiding treatment changes and improving the patient's quality of life.
\end{abstract}

Keywords: atopic dermatitis; dupilumab; Malassezia furfur; immunoglobulin E; itraconazole; head and neck pattern; ketoconazole; fluconazole

\section{Introduction}

Atopic dermatitis (AD) is one of the most prevalent chronic inflammatory diseases [1] Head and neck (H\&N) involvement, also known as portrait dermatitis [2], can be a diagnostic and even therapeutic challenge in some patients [3]. Since the introduction of dupilumab in 2017 for the treatment of adult severe AD, several adult-specific articles on this pattern have been published. In addition, this location of eczema significantly compromises the quality of life of patients with AD [4]. Experience of H\&N AD that does not improve with dupilumab in real-world clinical practice may be a reason to discontinue biologic therapy. Sensitization to the fungus Malassezia furfur seems to be implicated in this clinical presentation [5,6]. Based on this background, the aim of the present study was to investigate the role of specific IgE for Malassezia furfur in patients with AD, mainly as a cause of H\&N pattern.

\section{Material and Methods}

We performed a single-centre observational pilot study at the Department of Contact Eczema and Immunoallergy of the Hospital Universitario San Cecilio de Granada, Spain. Patient recruitment took place from 1 February 2020 to 30 June 2020. Inclusion criteria were 
patients over 18 years of age diagnosed with AD who were under follow-up and treatment in our department. Exclusion criteria were refusal to participate in the study, refusal to take the blood test for the determination of specific IgE, and current antifungal treatment (both oral and topical) for another dermatological disease. Demographic, clinical, and serological data collected were patient age, sex, H\&N involvement, total IgE serum levels, IgE levels for Malassezia furfur, lactate dehydrogenase (LDH) levels, and C-reactive protein (CRP) levels (Table 1).

Table 1. Demographic, clinical, and serological characteristics.

\begin{tabular}{|c|c|c|c|}
\hline & Atopic Dermatitis & Seborrheic Dermatitis & Healthy Controls \\
\hline $\mathrm{n}$ & 25 & 14 & 19 \\
\hline Age, years (mean \pm SD) & $31.92 \pm 10.26$ & $38.64 \pm 17.08$ & $36.58 \pm 13.32$ \\
\hline Sex ratio $(\mathrm{M} / \mathrm{F})$ * & 0.48 & 0.79 & 0.63 \\
\hline Weight (mean \pm SD) & $73.24 \pm 16.22$ & $82.86 \pm 4.88$ & $72.11 \pm 9.78$ \\
\hline H\&N involvement * & $68 \%$ & $100 \%$ & $0 \%$ \\
\hline Asthma history * & $52 \%$ & $0 \%$ & $5 \%$ \\
\hline Pneumoallergens history * & $88 \%$ & $15 \%$ & $0 \%$ \\
\hline Total IgE, IU $/ \mathrm{mL}($ mean $\pm \mathrm{SD})$ * & $2210.96 \pm 3260.30$ & $241.37 \pm 481.33$ & $36.3 \pm 54.56$ \\
\hline M. furfur IgE > 0.35 (Ku.arb./L) * & $80 \%$ & $0 \%$ & $0 \%$ \\
\hline Total LDH level (U/L) & $211.44 \pm 53.62$ & $205.33 \pm 35.20$ & $189.83 \pm 21.71$ \\
\hline Total CRP level (mg/L) & $1.44 \pm 0.82$ & $3.08 \pm 2.40$ & $1.96 \pm 0.99$ \\
\hline
\end{tabular}

* Statistically significant differences $(p<0.05)$.

\section{Statistical Analysis}

Data were expressed as the mean and standard deviation (SD) for quantitative continuous variables or as proportions-expressed as percentages_for categorical variables. Associations between categorical variables were assessed using Fisher's exact test. A Kruskal-Wallis test was performed for continuous variables across the different groups. Correlations between IgE levels for Malassezia furfur and other serological quantitative variables were assessed using Spearman's rank correlation coefficient analysis. $p$-values $<0.05$ were considered statistically significant. All statistical analyses were performed using Stata statistical software (V6.1; StataCorp, College Station, TX, USA).

\section{Results}

Table 1 shows the demographic, clinical, and serological characteristics of the patients included in the study. A total of 25 patients with AD (15 receiving dupilumab therapy), 14 patients with seborrheic dermatitis, and 19 healthy controls were enrolled in the study. The mean age of the atopic dermatitis group was $31.92 \pm 10.26,38.64 \pm 17.08$ for the SD group, and $36.58 \pm 13.32$ for the healthy group. The $\mathrm{M} / \mathrm{F}$ sex ratio was 0.48 for the AD group, 0.79 for the SD group, and 0.63 for the healthy group. This difference was significant between patients with SD and healthy controls. The mean weight of the AD group was $73.24 \pm 16.22,82.86 \pm 4.88$ for the SD group, and $72.11 \pm 9.78$ for the healthy group. The three groups were comparable with each other in age, sex, and weight. H\&N pattern involvement was observed in $68 \%$ of all AD patients, whereas $100 \%$ of DS patients showed $H \& N$ involvement. No patients in the healthy group showed H\&N involvement. The difference was statistically significant among all the groups. Within the group of patients with atopic dermatitis, $93.3 \%$ of patients on dupilumab treatment showed hypersensitivity to Malassezia furfur, versus $60 \%$ of patients with atopic dermatitis without dupilumab treatment. However, this difference was not significant $(p>0.05)$. The prevalence of asthma and pneumoallergen positivity was significantly higher in patients with AD than in patients with DS and healthy patients, with no differences between the latter two groups. Among AD patients, 52\% had associated asthma, 5\% of patients in the healthy group had associated asthma, whereas none of the patients in the SD group had associated asthma. Pneumoallergen sensitization was detected in $88 \%$ of patients in the AD group, $15 \%$ in the SD group, and no patients in the healthy group showed sensitization to pneumoallergens. 
Total IgE levels in serum were $2210.96 \pm 3260.30$ for the AD group, $241.37 \pm 481.33$ for the SD group, and $36.3 \pm 54.56$ for the healthy group, showing significance differences between the three groups. Specific IgE determination against Malassezia furfur (considered positive with a value equal to or higher than $0.35 \mathrm{Ku}$.arb./L) was $80 \%$ in the AD group, whereas no patient in the SD or healthy group showed specific IgE positivity. With regard to blood inflammatory markers, LDH levels were 211.44 \pm 53.62 for the AD group, $205.33 \pm 35.20$ for the SD group, and $189.83 \pm 21.71$ for the healthy group. Although no statistically significant differences were found between the groups, AD patients showed higher mean $\mathrm{LDH}$ levels than the other groups. Total CRP was $1.44 \pm 0.82$ for the AD group, $3.08 \pm 2.40$ for the SD group, and $1.96 \pm 0.99$ for the healthy group. No statistical differences were detected for CRP levels between the groups.

Table 2 shows these same characteristics within patients with atopic dermatitis after being divided into two groups according to whether or not they were under treatment with dupilumab. These two subgroups show significant differences in two parameters, weight and $H \& N$ involvement, affecting $100 \%$ of patients on dupilumab versus only $20 \%$ of those not on dupilumab.

Table 2. Subgroups of DA patients according to dupilumab treatment.

\begin{tabular}{|ccc}
\hline & Dupilumab & No Dupilumab \\
\hline n & 15 & 10 \\
\hline Age, years (mean \pm SD) & $34.33 \pm 10.97$ & $28.30 \pm 8.33$ \\
Sex ratio (M/F) & 0.60 & 0.30 \\
Weight (mean \pm SD) * & $79.53 \pm 16.42$ & $63.80 \pm 10.84$ \\
H\&N involvement * & $100 \%$ & $20 \%$ \\
\hline Asthma history & $47 \%$ & $60 \%$ \\
\hline Pneumoallergens history & $87 \%$ & $90 \%$ \\
Total IgE, IU /mL (mean \pm SD) & $1772.48 \pm 3053.84$ & $2868.67 \pm 3610.73$ \\
M. furfur IgE $>$ 0.35 (Ku.arb./L) & $93 \%$ & $60 \%$ \\
\hline Total LDH level (U/L) & $201.93 \pm 22.76$ & $225.7 \pm 80.53$ \\
Total CRP level (mg/L) & $1.47 \pm 0.92$ & $1.40 \pm 0.71$ \\
\hline
\end{tabular}

* Statistically significant differences $(p<0.05)$.

Statistical analysis showed a statistically significant correlation between Malassezia furfur-specific IgE levels and the following serological variables: elevated total IgE levels $(p=0.000)$, sensitization to different pneumoallergens $(p<0.001)$, and elevated CRP levels $(p=0.010)$. In addition, this positive association was also found with current treatment with dupilumab $(p=0.001)$. However, no significant relationship was found between Malassezia furfur-specific IgE levels and variables such as sex, severity of AD (measured by the Eczema Area and Severity Index (EASI), body surface area (BSA), and Investigator Global Assessment (IGA)), personal history of asthma or LDH levels. Patients with H\&N pattern AD and positive Malassezia furfur-specific $\operatorname{IgE}(\mathrm{n}=16)$ were treated with $100 \mathrm{mg}$ of itraconazole every $12 \mathrm{~h}$ for 3 weeks $(\mathrm{n}=2)$ (Figure 1$)$, ketoconazole $2 \%$ cream every $12 \mathrm{~h}$ for 3 weeks $(n=3)$ (Figure 2), or both therapies $(n=11)$ (Figure 3$)$, depending on the extent and severity of the lesions. 


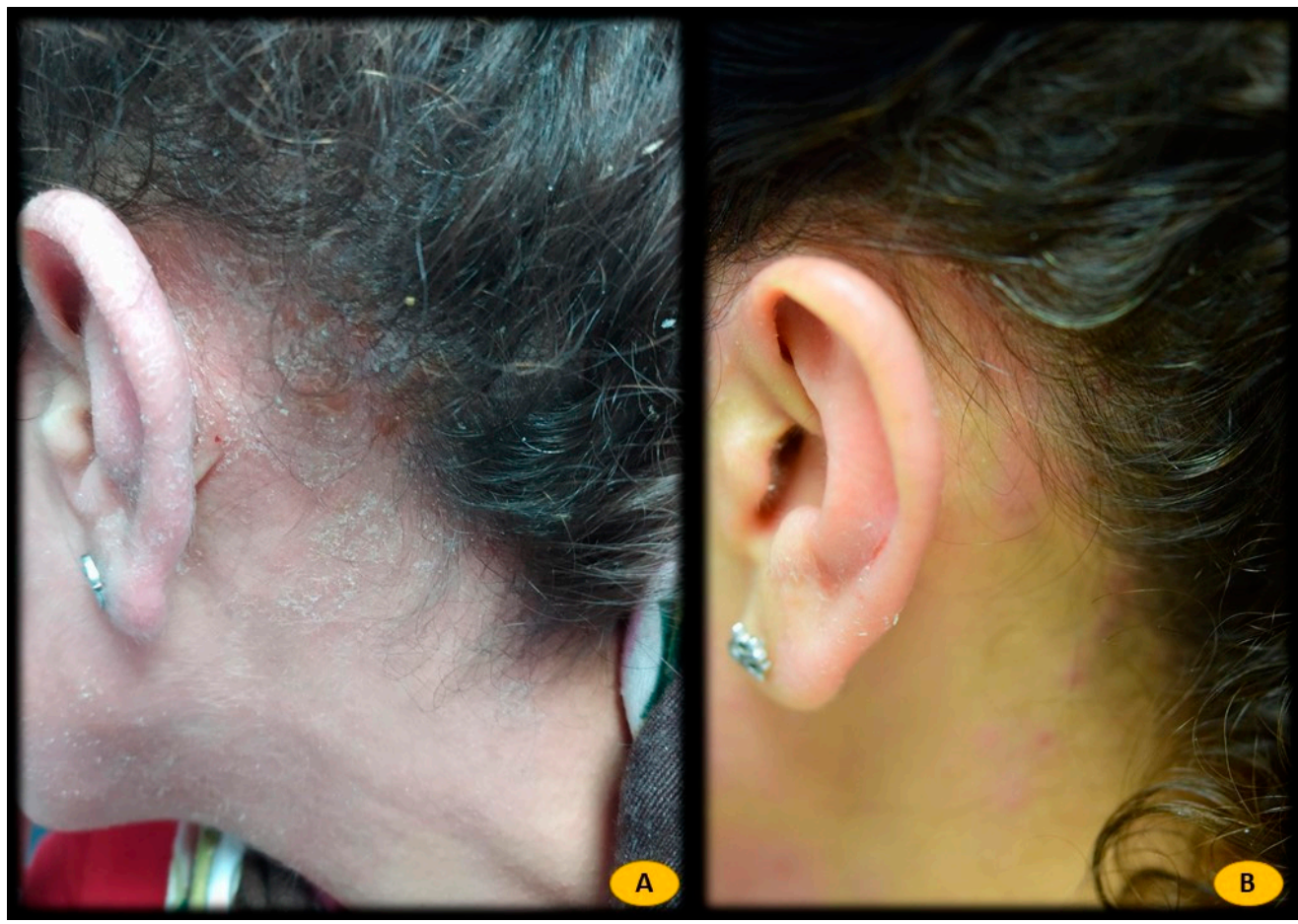

Figure 1. (A) Patient with atopic dermatitis $H \& N$ pattern treated with dupilumab. Positive IgE for Malassezia furfur (17.40 Ku.arb./L). (B) After 3 weeks of treatment with itraconazole $100 \mathrm{mg} / 12 \mathrm{~h}$ oral, almost complete response to treatment. Malassezia furfur-specific IgE levels of $1.2 \mathrm{Ku}$.arb./L.

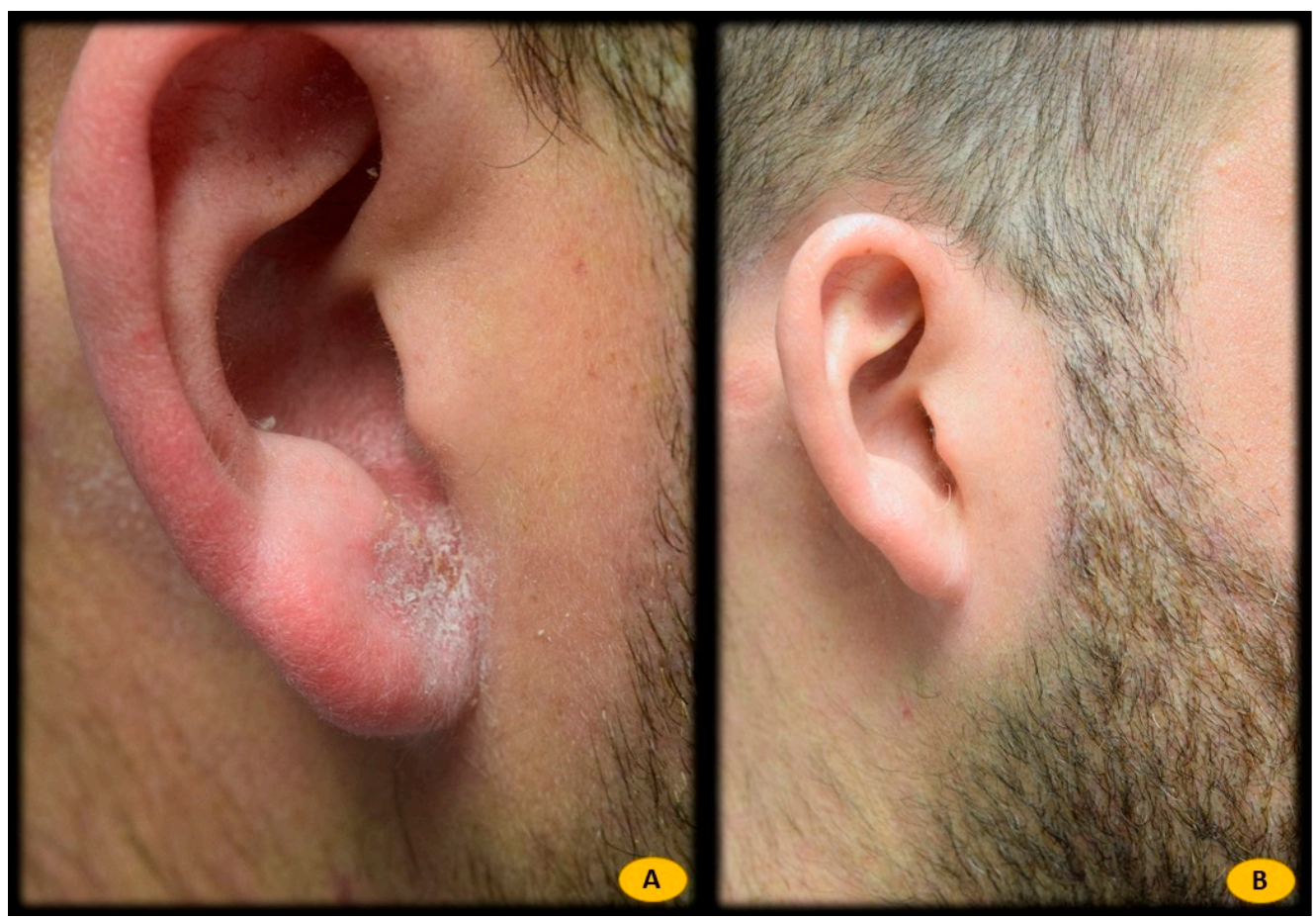

Figure 2. (A) Patient with atopic dermatitis H\&N pattern treated with dupilumab. Positive IgE for Malassezia furfur (0.88 Ku.arb./L). (B) After 3 weeks of treatment with ketoconazole $2 \%$ cream every $12 \mathrm{~h}$, complete response to treatment. Malassezia furfur-specific IgE levels < $0.1 \mathrm{Ku}$.arb./L. 


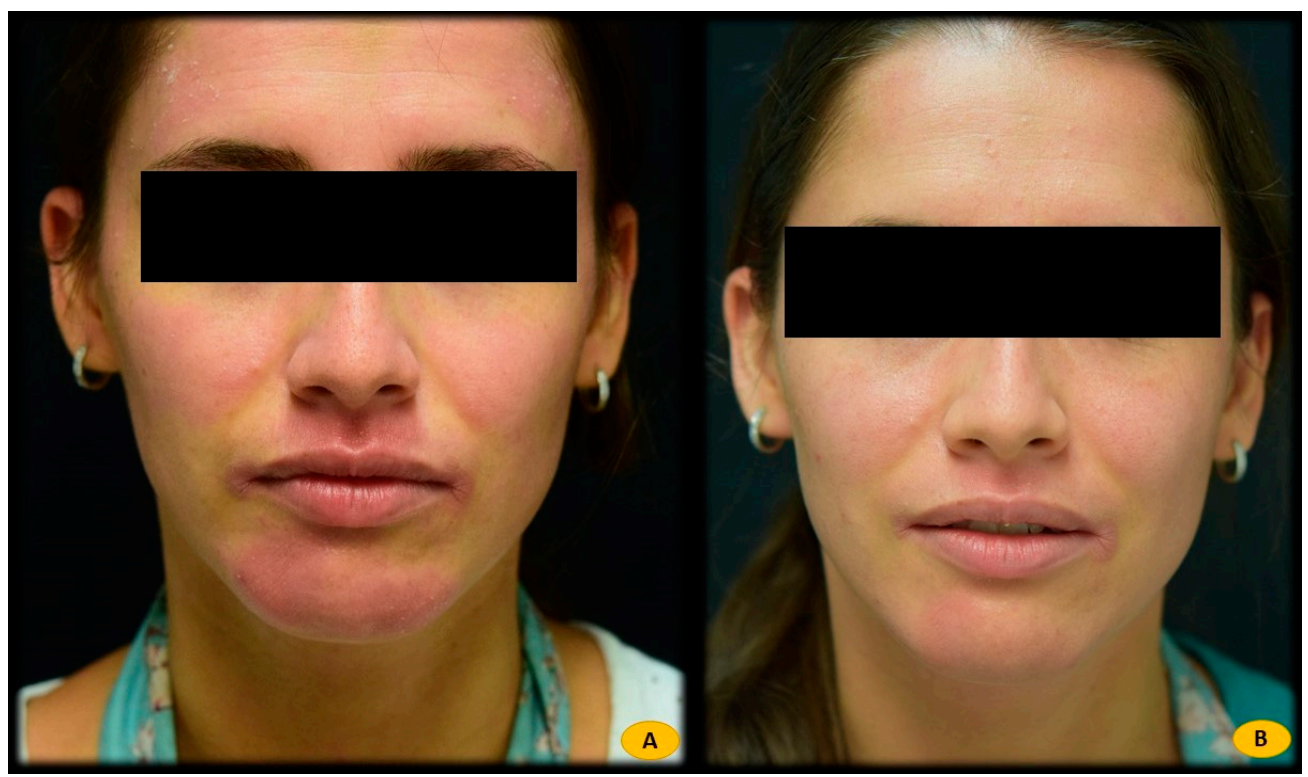

Figure 3. (A) Patient with atopic dermatitis H\&N pattern treated with dupilumab. Positive IgE for Malassezia furfur (48.80 Ku.arb./L). (B) After 3 weeks of treatment with itraconazole $100 \mathrm{mg} / 12 \mathrm{~h}$ oral and ketoconazole $2 \%$ cream every $12 \mathrm{~h}$, complete response to treatment. Malassezia furfur-specific IgE levels of 12.2 Ku.arb./L.

\section{Discussion}

Blocking the Th2 pathway using biological therapies such as dupilumab is a successful therapeutic strategy in patients with AD [7]. This type of inflammatory pathway is involved in the homeostasis between the human microbiome and colonising microorganisms. These include the fungal family Malassezia spp. [8,9]. These lipophilic fungi require an alkaline $\mathrm{pH}$ for growth. They usually colonise the skin from puberty onwards. The skin changes seen in AD allow Malassezia spp. to colonise the skin more easily. Changes in the immune system observed in AD skin, with decreased cathelicidins (LL37) and decreased $\beta$-defensins, also favour the colonisation of this fungus. Through mannan receptors expressed on dendritic cells, Malassezia spp. proteins are recognised by the innate immune system [10]. In addition, colonization of Malassezia spp. on the skin induces the release of cytokines, such as TNF- $\alpha$, IL1 $\beta$, and IL18 (without IL12). All this leads to antigen presentation to Th2 lymphocytes, with the release of IL13 [11]. This cytokine maintains homeostasis between the organism and colonisation by Malassezia spp. Blocking the Th2 pathway with drugs such as dupilumab induces an immune shift with increased activation of the Th17/Th22mediated pathway. It has been shown in mouse models that overexpression of Th17/Th22 mediates the inflammatory hypersensitivity reaction to $M$. furfur fungal proteins [12]. It is therefore not surprising that psoriasiform rashes are observed in AD patients treated with dupilumab [13]. Similarly, seborrheic dermatitis-like rashes may also be seen in this same patient profile. In our study, no psoriasiform eruptions were observed in patients with AD in either the dupilumab-treated or the non-dupilumab-treated subgroups.

Although the pilot study was initially designed with two groups for comparison, the DS and the healthy group, we soon observed that the determination of IgE specific for Malassezia furfur in DS patients was negative in all patients. DS is considered to be an inflammatory dermatosis in response to this fungus, triggered by a mechanism different from that observed for IgE-mediated sensitization. No patient in the DS group showed IgE positivity specific for Malassezia furfur. The determination of this biomarker could be considered an interesting analytical tool to differentiate those cases of $A D$ with $H \& N$ pattern from true DS. In facial DS, decreased diversity of the microbiome has been demonstrated with an increased Malassezia population [14]. This change in the skin microbiome is responsible for the inflammatory reaction mediated mainly by the innate immune system. 
The application of ketoconazole cream reduces the colonisation of Malassezia furfur and thus restores the microbiome.

Malassezia spp.-induced H\&N pattern is characterised by seborrheic eczematous lesions in classic areas (ciliary, nasolabial fold, anterior cervical face), as well as on the scalp. It usually worsens with sweating and shows no improvement with conventional topical anti-inflammatory treatments (corticosteroids and topical calcineurin inhibitors). To date, the use of dupilumab has not been associated as a risk factor for this condition. However, in our study, we found a significant relationship between dupilumab, H\&N AD pattern, and Malassezia furfur-specific IgE positivity.

Another interesting aspect to note was the location of the lesions in the group of patients with AD without sensitization to Malassezia furfur fungus. None of the patients had lesions on the head and/or neck. All showed a classic flexural pattern, with involvement of the popliteal and antecubital folds.

Regarding treatment, there are published cases in the literature with variable responses with fluconazole $150 \mathrm{mg} /$ weekly [15]. In our experience, itraconazole $100 \mathrm{mg} / 12 \mathrm{~h}$ for 3 weeks showed a full or almost full response. The antifungal and anti-inflammatory effect of itraconazole may account for this successful therapeutic response [16]. In mild H\&N AD cases, ketoconazole $2 \%$ cream every $12 \mathrm{~h}$ may be indicated, with satisfactory responses in these patients [17]. Oral itraconazole and topical ketoconazole may be combined when the clinical situation requires it-mainly patients with more extensive lesions. Overlapping cases with eczematous lesions may require combination with topical anti-inflammatory treatments, such as corticosteroids or topical calcineurin inhibitors.

Other possible etiologies should be taken into account in the workup of patients with H\&N pattern AD. Palpebral involvement suggests allergic contact dermatitis, which requires patch testing. Facial erythematous patches may represent the specific picture induced by dupilumab (dupilumab-associated head and neck dermatitis (DAFND). Rosaceiform/demodicosis rashes, the pathophysiology of which is also mediated by Th2 pathway blockade and polarization towards Th17 [18], should also not be forgotten. The possibility of overlap between all these entities is possible, so it is necessary to be familiar with the clinical clues to properly approach the treatment of each patient. The main diseases that comprise the differential diagnosis of H\&N AD pattern can be found in Table 3.

Table 3. Differential diagnosis of H\&N atopic dermatitis pattern.

\begin{tabular}{|c|c|c|}
\hline $\begin{array}{c}\text { Dermatological } \\
\text { Diseases }\end{array}$ & Clinical Features & Diagnostic Approach \\
\hline $\begin{array}{l}\text { Dupilumab facial } \\
\text { redness }\end{array}$ & $\begin{array}{c}\text { Fixed erythema located on the face or neck (may also } \\
\text { occur extrafacially) } \\
\text { Usually unilateral } \\
\text { Resistant to corticosteroids and / or topical } \\
\text { calcineurin inhibitors } \\
\text { Patient on dupilumab treatment }\end{array}$ & $\begin{array}{c}\text { Clinical } \\
\text { Temporal correlation between dupilumab } \\
\text { initiation and onset of erythema red } \\
\text { facial erythema }\end{array}$ \\
\hline $\begin{array}{l}\text { Seborrhoeic } \\
\text { dermatitis }\end{array}$ & $\begin{array}{l}\text { Pityriasiform lesions (whitish "dry" scale) over orange } \\
\text { erythema on nasolabial folds, ciliary area, beard or } \\
\text { sideburn area, scalp or external auditory canal. }\end{array}$ & Clinical \\
\hline Rosacea & $\begin{array}{c}\text { Persistent malar erythema or with flushing exacerbations } \\
\text { Telangiectasias of different calibre } \\
\text { Papules and/or pustules }\end{array}$ & $\begin{array}{c}\text { Clinical } \\
\text { Dermoscopy } \\
\text { Microscopic examination of Demodex } \\
\text { folliculorum with tape test, scraping, etc. }\end{array}$ \\
\hline Demodicosis & $\begin{array}{c}\text { Facial itching and/or burning sensation (especially on } \\
\text { the cheeks) } \\
\text { Erythematous dilatation of facial follicular openings seen } \\
\text { on dermoscopy }\end{array}$ & $\begin{array}{c}\text { Clinical } \\
\text { Dermoscopy } \\
\text { Microscopic examination of Demodex } \\
\text { folliculorum with tape test, scraping, etc. }\end{array}$ \\
\hline
\end{tabular}


Table 3. Cont.

\begin{tabular}{|c|c|c|}
\hline $\begin{array}{l}\text { Dermatological } \\
\text { Diseases }\end{array}$ & Clinical Features & Diagnostic Approach \\
\hline Dermatitis perioralis & $\begin{array}{c}\text { Monomorphous papular rash localised in the } \\
\text { perioral region } \\
\text { Asymptomatic }\end{array}$ & Clinical \\
\hline $\begin{array}{l}\text { Allergic contact } \\
\text { dermatitis }\end{array}$ & $\begin{array}{c}\text { Erythematous, scaly, very pruritic rash. Special patterns: } \\
\text { palpebral, hairline, lateral facial and cervical sides, } \\
\text { usually symmetrical }\end{array}$ & $\begin{array}{l}\text { Patch testing with standard and } \\
\text { specific series }\end{array}$ \\
\hline Airborne dermatitis & $\begin{array}{c}\text { Facial and cervical erythematous-squamous rash, with } \\
\text { involvement of the eyelids, retroauricular, and } \\
\text { submandibular areas. } \\
\text { Respect of the nasal triangle }\end{array}$ & $\begin{array}{l}\text { Allergological study by means of: } \\
\text { - Specific IgE in serum for pneumoallergens. } \\
\text { - Allergen specific prick test }\end{array}$ \\
\hline $\begin{array}{l}\text { Malassezia head/ } \\
\text { neck dermatitis }\end{array}$ & $\begin{array}{c}\text { Facial and cervical rash mainly localised in } \\
\text { seborrheic-like areas } \\
\text { Patients on dupilumab treatment } \\
\text { Age from adolescence onwards (infrequent in childhood) } \\
\text { Refractoriness to topical corticosteroids and/or topical } \\
\text { calcineurin inhibitors } \\
\text { May appear de novo or be persistent after starting } \\
\text { dupilumab treatment }\end{array}$ & $\begin{array}{l}\text { Malassezia furfur-specific IgE serum } \\
\qquad(>0.35 \mathrm{IU} / \mathrm{mL}) \\
\text { Clinical response to treatment with topical } \\
\text { and/or oral antifungals }\end{array}$ \\
\hline $\begin{array}{l}\text { Topical steroid } \\
\text { withdrawal }\end{array}$ & $\begin{array}{l}\text { More frequent in women } \\
\text { Prolonged use of topical corticosteroids } \\
\text { Erythematous hypersensitive skin appearance } \\
\text { Local sensation of itching, heat, pain, burning, etc. }\end{array}$ & $\begin{array}{l}\text { Anamnesis (confirmation of chronic use of } \\
\text { topical corticosteroids on the face) } \\
\text { Clinical }\end{array}$ \\
\hline
\end{tabular}

For the study of sensitization to Malassezia spp., there are other methods besides the determination of specific IgE. Studies with prick tests or patch tests are available [19]. However, in favour of serum specific IgE, we can point out that there are more published studies on this method and that it offers the advantage of being more accessible for the physician, without extraordinary time consumption for the patient. The main limitation of our study is the small number of patients included. The study was designed as a pilot study with patients registered during the recruitment period.

In conclusion, we present the study of sensitization to M. furfur in patients with $\mathrm{AD}$ and $H \& N$ pattern. The results are in line with our study objective, where sensitization to Malassezia furfur in patients with atopic dermatitis may be a cause of H\&N pattern. Risk factors to consider include high total IgE levels, sensitization to pneumoallergens, CRP levels, and receiving dupilumab treatment. The most appropriate treatment seems to be the use of oral itraconazole and/or ketoconazole cream. We can add that the determination of Malassezia furfur-specific IgE can be considered a useful biomarker for diagnosis and therapeutic indication in $\mathrm{H} \& \mathrm{~N}$ AD pattern.

Author Contributions: Conceptualization, F.J.N.-T. and Á.A.-R.; methodology, F.J.N.-T. and Á.A.-R.; software, F.J.N.-T. and Á.A.-R.; validation, F.J.N.-T. and Á.A.-R.; formal analysis, F.J.N.-T. and Á.A.-R. investigation, F.J.N.-T. and Á.A.-R.; resources, F.J.N.-T. and Á.A.-R.; data curation, F.J.N.-T. and Á.A.-R. writing—original draft preparation F.J.N.-T. and Á.A.-R.; writing—review and editing, F.J.N.-T. and Á.A.-R.; visualization, F.J.N.-T. and Á.A.-R. supervision, F.J.N.-T. and Á.A.-R.; project administration, F.J.N.-T. and Á.A.-R.; funding acquisition, None. All authors have read and agreed to the published version of the manuscript.

Funding: This research received no external funding.

Institutional Review Board Statement: Not applicable.

Informed Consent Statement: Informed consent was obtained from all subjects involved in the study.

Data Availability Statement: Not applicable. 
Conflicts of Interest: The authors declare no conflict of interest.

\section{References}

1. Hadi, H.A.; Tarmizi, A.I.; Khalid, K.A.; Gajdács, M.; Aslam, A.; Jamshed, S. The Epidemiology and Global Burden of Atopic Dermatitis: A Narrative Review. Life 2021, 11, 936. [CrossRef] [PubMed]

2. Nettis, E.; Ortoncelli, M.; Pellacani, G.; Foti, C.; Di Leo, E.; Patruno, C.; Rongioletti, F.; Argenziano, G.; Ferrucci, S.M.; Macchia, L.; et al. A Multicenter Study on the Prevalence of Clinical Patterns and Clinical Phenotypes in Adult Atopic Dermatitis. J. Investig. Allergol. Clin. Immunol. 2020, 30, 448-450. [CrossRef] [PubMed]

3. Jaros, J.; Hendricks, A.J.; Shi, V.Y.; Lio, P.A. A Practical Approach to Recalcitrant Face and Neck Dermatitis in Atopic Dermatitis. Dermatitis 2020, 31, 169-177. [CrossRef] [PubMed]

4. Ribero, S.; Puglisi, B.; Giura, M.T.; Viola, R.; Siliquini, N.; Quaglino, P.; Ortoncelli, M. Head and neck severity index is associated to a significant worsening of quality of life in atopic dermatitis patients. Exp. Dermatol. 2021, 30, 1717-1718. [CrossRef] [PubMed]

5. Bayrou, O.; Pecquet, C.; Flahault, A.; Artigou, C.; Abuaf, N.; Leynadier, F. Head and neck atopic dermatitis and Malassezia-furfurspecific IgE antibodies. Dermatology 2005, 211, 107-113. [CrossRef] [PubMed]

6. Zhang, E.; Tanaka, T.; Tajima, M.; Tsuboi, R.; Kato, H.; Nishikawa, A.; Sugita, T. Anti-Malassezia-Specific IgE Antibodies Production in Japanese Patients with Head and Neck Atopic Dermatitis: Relationship between the Level of Specific IgE Antibody and the Colonization Frequency of Cutaneous Malassezia Species and Clinical Severity. J. Allergy 2011, 2011, 645670. [CrossRef] [PubMed]

7. Benzecry, V.; Pravettoni, V.; Segatto, G.; Marzano, A.V.; Ferrucci, S. Type 2 Inflammation: Atopic Dermatitis, Asthma, and Hypereosinophilia Successfully Treated With Dupilumab. J. Investig. Allergol. Clin. Immunol. 2021, 31, 261-263. [CrossRef] [PubMed]

8. Koh, L.F.; Ong, R.Y.; Common, J.E. Skin microbiome of atopic dermatitis. Allergol. Int. 2021, 71, 31-39. [CrossRef] [PubMed]

9. Tao, R.; Li, R.; Wang, R. Dysbiosis of skin mycobiome in atopic dermatitis. Mycoses 2021. [CrossRef] [PubMed]

10. Aspres, N.; Anderson, C. Malassezia yeasts in the pathogenesis of atopic dermatitis. Australas. J. Dermatol. 2004, 45, 199-207. [CrossRef] [PubMed]

11. Buentke, E.; Zargari, A.; Heffler, L.C.; Avila-Cariño, J.; Savolainen, J.; Scheynius, A. Uptake of the yeast Malassezia furfur and its allergenic components by human immature CD1a+ dendritic cells. Clin. Exp. Allergy 2000, 30, 1759-1770. [CrossRef] [PubMed]

12. Buentke, E.; Heffler, L.C.; Wallin, R.P.A.; Löfman, C.; Ljunggren, H.G.; Scheynius, A. The allergenic yeast Malassezia furfur induces maturation of human dendritic cells. Clin. Exp. Allergy 2001, 31, 1583-1593. [CrossRef]

13. Jaulent, L.; Staumont-Sallé, D.; Tauber, M.; Paul, C.; Aubert, H.; Marchetti, A.; Sassolas, B.; Valois, A.; Nicolas, J.; Nosbaum, A.; et al. De novo psoriasis in atopic dermatitis patients treated with dupilumab: A retrospective cohort. J. Eur. Acad. Dermatol. Venereol. 2021, 35, e296-e297. [CrossRef]

14. Tao, R.; Wang, R.; Wan, Z.; Song, Y.; Wu, Y.; Li, R. Ketoconazole 2\% Cream Alters the Skin Fungal Microbiome in Seborrheic Dermatitis: A Cohort Study. Clin. Exp. Dermatol. 2022. [CrossRef] [PubMed]

15. Kaffenberger, B.H.; Mathis, J.; Zirwas, M.J. A retrospective descriptive study of oral azole antifungal agents in patients with patch test-negative head and neck predominant atopic dermatitis. J. Am. Acad. Dermatol. 2014, 71, 480-483. [CrossRef] [PubMed]

16. De Beer, F.S.A.; Bakker, D.S.; Haeck, I.; Ariens, L.; van der Schaft, J.; van Dijk, M.R.; de Bruin-Weller, M.S. Dupilumab facial redness: Positive effect of itraconazole. JAAD Case Rep. 2019, 5, 888-891. [CrossRef] [PubMed]

17. Okiyama, N.; Nakamura, Y.; Ishitsuka, Y.; Inoue, S.; Kubota, N.; Saito, A.; Watanabe, R.; Fujisawa, Y.; Igawa, K. Successful topical treatment with ketoconazole for facial rashes refractory to dupilumab in patients with atopic dermatitis: Case reports. J. Eur. Acad. Dermatol. Venereol. 2020, 34, e474-e476. [CrossRef] [PubMed]

18. Amir Ali, A.; Vender, R.; Vender, R. The Role of IL-17 in Papulopustular Rosacea and Future Directions. J. Cutan. Med. Surg. 2019, 23, 635-641. [CrossRef] [PubMed]

19. Johansson, C.; Eshaghi, H.; Linder, M.T.; Scheynius, A.; Jakobson, E. Positive Atopy Patch Test Reaction to Malassezia furfur in Atopic Dermatitis Correlates with a T Helper 2-like Peripheral Blood Mononuclear Cells Response. J. Investig. Dermatol. 2002, 118, 1044-1051. [CrossRef] [PubMed] 